\title{
Effects of hydrogen assisted stress corrosion on damage tolerance of a high-strength duplex stainless steel wire for prestressing concrete
}

\author{
M. de Abreu, M. Iordachescu , A. Valiente
}

Keywords:

High-strength duplex stainless steel

Prestressing wire

Hydrogen assisted damage FIP stress

corrosion test

Damage tolerance

\begin{abstract}
A B S T R A C T
The study brings new insights on the hydrogen assisted stress corrosion on damage tolerance of a highstrength duplex stainless steel wire which concerns its potential use as active reinforcement for concrete prestressing. The adopted procedure was to experimentally state the effect of hydrogen on the damage tolerance of cylindrical smooth and precracked wire specimens exposed to stress corrosion cracking using the aggressive medium of the standard test developed by FIP (International Prestressing Federation). Stress corrosion testing, mechanical fracture tests and scanning electron microscopy analysis allowed the damage assessment, and explain the synergy between mechanical loading and environment action on the failure sequence of the wire. In presence of previous damage, hydrogen affects the wire behavior in a qualitative sense, consistently to the fracture anisotropy attributable to cold drawing, but it does not produce quantitative changes since the steel fully preserves its damage tolerance.
\end{abstract}

\section{Introduction}

Prestressing concrete is a major finding in civil engineering, based on artificially induced internal stresses to prevent concrete from tensile stresses when external loads act. Since this occurs at the expense of prestressing steel, which is heavily tensile loaded during prestressing concrete, the technique requires steels of extremely high tensile strength and moderate cost. Today, these two conditions are satisfied by applying cold-drawing as manufacturing technique to high-carbon eutectoid steels. Therefore, most of the currently produced prestressing steels with tensile strength ranging from 1600 to $1800 \mathrm{MPa}$ are cold-drawn wires and strands, and to a less extent, quenched and tempered bars.

Prestressing steel is the most critical component of prestressing concrete structures. Often, its failure involves the collapse of the whole structure. Then, damage resistance and damage tolerance are properties that must be required from prestressing steel to the same extent that damage is propitiated by the service conditions of the structure. In practice, the minimum $3.5 \%$ of uniform elongation required to cold-drawn wires for prestressed concrete [1] assures the damage tolerance level intrinsic to ductile steels [2].

In contrast to reinforced concrete, prestressed concrete is free of cracks due to the absence of tensile stresses, but this does not suppress the risk of corrosion damage of prestressing steel by environmental attack. The collapse of prestressing concrete structures originated by corrosion has occasionally occurred for years $[3,4]$. Once disregarded the cases originated by defective steel or underestimated environmental aggressiveness, the susceptibility to stress corrosion cracking is the feature that governs the corrosion failure of the prestressing steel products [3].

Stress corrosion cracking is a localized damage process resulting from the combined action of tensile stresses and environmental attack. Models of stress corrosion cracking range from the cracking dissolution of the metal to its local embrittlement due to the uptake of damaging species, as dissociated hydrogen. There is a general agreement that hydrogen uptake is the dominant and most 
dangerous stress corrosion cracking mechanism for prestressing steels [5-7].

Protection systems consisting of mechanical or electrochemical barriers to the aggressive media are available, but experience shows that they are doubtfully effective, if not counterproductive [8]. As consequence, two technological testing procedures, FIP and DIBt, were respectively developed by FIP (International Prestressing Federation) and DIBt (German Institute of Structural Engineering), in order to assess the resistance to stress corrosion cracking of prestressing steel [6,9]. Both tests, designed to promote hydrogen uptake into prestressing steel, are standardized [9]. Even though their discriminating power is similar, they differ in the aggressiveness of the employed media and consequently in the test duration [10].

Stainless steel is a structural metallic material with great potential of being used in prestressed concrete due to its excellent corrosion resistance and its ability to be cold worked. Furthermore, stainless steel products are widely used in the construction industry as passive reinforcements of concrete and as mechanical connectors for constructional details [11]. Then, strength and ductility levels typical of prestressing steel can be obtained by deep cold drawing of stainless steel up to $80 \%$ reduction in cross sectional area [12-14].

However, cold drawing can give rise to the transformation of austenite into martensite, in both austenitic and duplex stainless steels [15]. Then, strain-induced martensite reduces the corrosion resistance of stainless steel in two ways [16]: by forming with austenite a galvanic corrosion micro-cell that favors pitting corrosion and by providing to hydrogen both a penetration path and a microstructural component easy to embrittle. In austenitic stainless steels the alloying elements such as $\mathrm{Ni}, \mathrm{Mn}$ and $\mathrm{Cu}$ are austenite stabilizers and mitigate the volume fraction of strain-induced martensite $[16,17]$. In duplex grade steels, strain-induced martensite fraction depends on the volume fractions of austenitic and ferritic phases and the cold drawing level [18]. Their corrosion resistance is considerable improved by additional alloying elements such as Mo and $\mathrm{N}[18,19]$.

So far, more attention has been paid to pitting corrosion of cold-drawn austenitic and, to a less extent, to duplex stainless steel, when exposed to the most aggressive environment found in prestressed concrete, given by the carbonated concrete with high concentration of chlorides. However, previously reported results on corrosion resistance of duplex steels wires are highly satisfactory, especially when containing fractions of Mo ranging from $2 \%$ to $3 \%$, are enhancing their potential use as prestressing steels $[13,14]$.

In contrast to pitting corrosion resistance of cold-drawn wire of stainless steel $[11,16,18]$, few data concerning its resistance to hydrogen assisted stress corrosion cracking are available; four austenitic and one duplex steel wire of different Mo content have been FIP tested [16,17]. Only the tests performed with the austenitic steel, Mo free, resulted in catastrophic failure; even though, the wire lifetime was much longer than that expected from any existent eutectoid prestressing steel [16,17].

In this research, the previously assessed results of [2] regarding the damage the tolerance of cold drawn duplex 1.4462 stainless steel wires are extended to damage caused by hydrogen embrittlement as stress cracking corrosion mechanism. The serious risk that this damage process entails to the integrity of prestressing concrete structures, the potential use of cold drawn duplex steel wire as prestressing steel, and the scant available data impelled the investigation.

The FIP testing method is adopted as the basic means of producing the hydrogen assisted damage to the examined duplex steel wire. Subsequent tensile testing and Scanning Electron Microscopy (SEM) analysis were used for the damage assessment. Fatigue pre-damaged wire specimens were also subjected to the FIP test in order to separate the hydrogen effects in the initiation and propagation stages of the damage process.

\section{Experimental details}

The tested high strength stainless steel is a 1.4462 duplex grade [20], industrially manufactured as a $4 \mathrm{~mm}$ diameter wire, by several passes of cold-drawing up to producing about $70 \%$ of cross section reduction. Such a cold-drawing process gives rise to a strongly orientated microstructure along the drawing direction and provides a mechanical resistance comparable to that of the eutectoid prestressing steels. The chemical composition of the tested 1.4462 duplex steel is given in Table 1.

Tensile properties of the wire were determined at room temperature [9], on samples of $450 \mathrm{~mm}$ length, as benchmark on evaluating its resistance to hydrogen assisted damage. The tensile tests were performed with a $200 \mathrm{kN}$ servohydraulic universal testing machine using a constant crosshead speed of $1 \mathrm{~mm} /$ min. Elongations were measured on a gauge length of $12.5 \mathrm{~mm}$ with a conventional clip-on extensometer. Table 2 shows the mechanical characteristics of the wire.

Three wire specimens (Fig. 1) were fatigue precracked from sharp notches of $0.5 \mathrm{~mm}$ depth, machined with a straight front perpendicular to the longitudinal axis of the wire. Fatigue precracking was performed by applying cyclic tensile loads ranging between 1 and $4 \mathrm{kN}$. An average number of 10,000 load cycles was applied to each specimen, at a frequency of $5 \mathrm{~Hz}$. To produce cracks of nominally equal size, a conventional clip-on extensometer, of $12.5 \mathrm{~mm}$ gauge length, was monitoring the fatigue crack growth through the elastic compliance of the notched zone. One of the precracked specimens was used to determine, by direct measurement, the wire bearing capacity in this damaged condition. The other two precracked specimens and a number of undamaged specimens, of same length, were dedicated to stress corrosion testing.

The damage tolerance of this wire steel had been previously obtained [2] by tensile breaking wire specimens, similarly precracked for a range of crack depths from 0.2 to 0.6 times the wire diameter.

The FIP test method was used to assess the susceptibility to stress corrosion of the prestressing steel wires [3]. It consists of constant tensile loading the wire specimen, immersed in a non-circulating corrosive solution of ammonium thiocyanate, maintained at constant temperature. The load is set to produce a constant stress equal to 0.8 times the tensile strength of the wire. The corrosive solution, of approximate $4.5 \mathrm{pH}$, contains $200 \mathrm{~g}$ of $\mathrm{NH}_{4} \mathrm{SCN}$ for each $800 \mathrm{ml}$ of distilled $\mathrm{H}_{2} \mathrm{O}$ is kept at $50^{\circ} \mathrm{C}$. The hydrogen embrittlement of the wire steel results from a cathodic stress corrosion mechanism [6]. The test result is the lifetime to fracture of the specimen. Normally, the test is stopped if fracture does not take place within $240 \mathrm{~h}$.

The specimens to be tested were rubbed with cotton dipped in butanone $\left(\mathrm{CH}_{3} \mathrm{COCH}_{2} \mathrm{CH}_{3}\right)$ and washed with isopropyl alcohol $\left(\mathrm{C}_{3} \mathrm{H}_{8} \mathrm{O}\right)$. Deionized water, of conductivity less than $0.5 \mu \mathrm{S} / \mathrm{cm}$, was used for preparing the corrosive solution. The tests were performed in double-walled thermostatic corrosion cells containing about 11 of the corrosive solution. An exposed length of about $20 \mathrm{~cm}$ was delimited at the central part of the wire specimen; an adhesive tape was used to avoid the differential aeration of the cell. The solution temperature was maintained at $50 \pm 1{ }^{\circ} \mathrm{C}$ through a continuous water flow, pumped in the external chamber of the cell from a thermostatic bath. The specimen was mechanically fastened to the load train with prestressing commercial anchorages and sealed in place. Once vertically anchored the specimen, the inner chamber of the cell was filled with the corrosive solution. The tensile load was immediately applied by hanging dead weights to a lever machine coupled to the loading train. A timer, which automatically stops once the specimen breaks, registered the testing time. The experimental arrangement is depicted in Fig. 2.

Three undamaged wire specimens and two precracked ones were tested according to the FIP procedure with the following variations regarding the applied load: two undamaged specimens were tensile stressed to $80 \%$ of the tensile strength of the wire, while the third was only stressed to $60 \%$. The precracked specimens were loaded to $80 \%$ of the failure load of an equally cracked wire, obtained by tensile testing, in air, the third precracked specimen.

The test procedure and the equipment used for tensile testing the cracked wire specimens as well as the cylindrical smooth wires, in as received or modified conditions, were the same as required in [9]; the clip-on extensometer, of $12.5 \mathrm{~mm}$ gauge length, was attached to the specimen in front of the crack.

Table 1

Chemical composition of the tested 1.4462 duplex steel (\% weight).

\begin{tabular}{llllllllll}
\hline $\mathrm{C}$ & $\mathrm{Si}$ & $\mathrm{Mn}$ & $\mathrm{P}$ & $\mathrm{S}$ & $\mathrm{N}$ & $\mathrm{Cr}$ & $\mathrm{Mo}$ & $\mathrm{Ni}$ & $\mathrm{Fe}$ \\
\hline \multirow{2}{*}{0.03} & 0.614 & \multirow{2}{*}{1.779} & 0.029 & 0.001 & 0.178 & 22.8 & \multirow{2}{*}{3.33} & \multirow{2}{*}{4.8} & Bal. \\
\hline
\end{tabular}


Table 2

Mechanical properties of the tested 1.4462 wire.

\begin{tabular}{lllll}
\hline $\begin{array}{l}\text { Elastic } \\
\text { modulus, } E\end{array}$ & $\begin{array}{l}\text { Yield } \\
\text { strength, } R_{p 0.2}\end{array}$ & $\begin{array}{l}\text { Tensile } \\
\text { strength, } R_{m}\end{array}$ & $\begin{array}{l}\text { Maximum uniform } \\
\text { elongation, } A_{5}\end{array}$ & $\begin{array}{l}\text { Reduction } \\
\text { in area, } Z\end{array}$ \\
\hline $160 \mathrm{GPa}$ & $1420 \mathrm{MPa}$ & $1660 \mathrm{MPa}$ & $2.2 \%$ & $70 \%$
\end{tabular}

\section{Results and discussion}

\subsection{Effect of FIP testing on undamaged wire}

The FIP tests of the three undamaged - cylindrical smooth specimens were stopped after $285 \mathrm{~h}$ without them having collapsed. Once removed from the aggressive solution and cleaned, they were examined by optical microscopy to detect corrosion pits that could activate the crack initiation mechanism described in [16] for cold drawn stainless steels. No significant signs of pitting corrosion related to crack initiation were found. Next, the specimens were tensile tested to determine eventual changes of mechanical behavior, as consequence of presumable damage induced by hydrogen.

Fig. 3 brings forward the experimentally obtained stress-strain curves of the previously FIP tested wires. For comparison, it also includes the stress-strain curve of the wire in the as received condition. The differences shown in Fig. 3 are better due to the plastic yielding and strain hardening of the wires, instead of attributing them to a presumable hydrogen induced damage that do not produces corrosion pits capable to initiate cracks. The points A and B

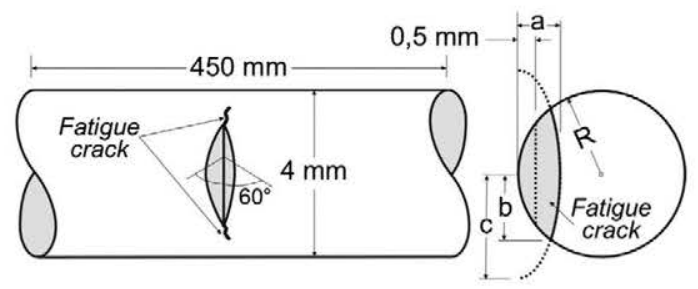

Fig. 1. Sketch of the fatigue precraked wire specimen showing the position and dimensions of the starter notch: $R$ - wire diameter; $a$ - crack depth; $2 b$ - distances between crack front ends; $c$ - semiaxis of the ellipse to which crack front is assimilated.

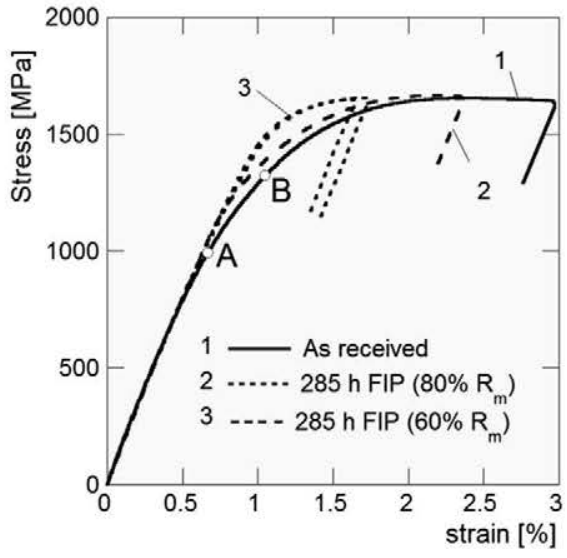

Fig. 3. Strain-stress curves of 1.4462 duplex steel wires: 1 - in as received condition; 2 - after $285 \mathrm{~h}$ of FIP test made at $80 \% R_{m} ; 3$ - after $285 \mathrm{~h}$ of FIP tests made at $60 \% R_{m}$; (A and B -plots of FIP loadings on the wire strain-stress curve; $R_{m}$ - wire tensile strength).

plotted in Fig. 3 on the stress-strain curve of the wire in the as received condition correspond to the stresses applied in the FIP tests, i.e., $0.60 R_{m}$ and $0.80 R_{m}\left(R_{m}\right.$ is the wire tensile strength). These stresses do not exceed the conventional yield strength of $0.85 R_{m}$, but they do exceed the stress from which the curve deviates from linearity. This occurs well prior to the conventional yield strength because plastic yielding and strain hardening gradually develop in stainless steels, even cold-drawn. Then, the stress of $0.60 R_{m}$ applied in the FIP test is insignificantly modifying the original pattern of the strain-stress curve, showing only a slight strain hardening of the steel, meanwhile the stress of $0.80 R_{m}$ indicates a more severe strain hardening, which sensitively increases the yield strength and drastically decreases the maximum uniform elongation. However, as presented in Fig. 3, the different loading levels applied in the FIP tests does not change the bearing load capacity of the wire, in accordance with a strain hardening process rather than a damage one, induced by hydrogen. This is also supported by the measured reductions in area, since the value of $70 \%$, given in Table 2 for the wires in the as-received condition, does not change in case of FIP tested specimens. This behavior strongly contrasts with that found in eutectoid prestressing steels, whose reduction in area decreases by more than a factor of 4 after $10 \mathrm{~h}$ of FIP test [21].

\subsection{Effect of FIP testing on fatigue precracked wire}

Fracture occurred in cold-drawn austenitic stainless steels during FIP testing or in subsequent tensile testing was observed to propagate from surface microcracks or brittle areas previously produced in presence of hydrogen [17]. This supports the rational of the above presented results, when assuming that hydrogen is not able to initiate the damage of the duplex tested wire, but it might contribute to the propagation stage of an existent one.

To gain an insight into this last issue, FIP test capacity to induce hydrogen damage in the duplex steel wire was further investigated by testing the two specimens previously fatigue precracked. The two specimens were loaded at 0.80 times the tensile failure load $P_{m}$ of a wire damaged by an equal crack. This load was obtained by tensile testing up to fracture the third precracked specimen. The test was carried out in air, at room temperature, as previously described.

The FIP tests were stopped and the specimens were removed from the ammonium thiocyanate solution after $240 \mathrm{~h}$ without them having collapsed. They were examined by optical microscopy with the same results concerning pitting corrosion as the non

Fig. 2. Experimental arrangement for stress corrosion FIP test. 
hydrogen atoms trapped in the grain boundaries produce the embrittlement of the interface between ferrite and austenite, favoring their transgranular decohesion. Secondarily, the interface between ferrite and austenite is the preferential region for trapping of hydrogen atoms in duplex stainless steels, explained by their relative low diffusivity when comparing to fully ferritic steels [22]. Lastly, hydrogen transport stands in with the high stresses developed at the fatigue crack tip by concentrating hydrogen atoms in this region.

The convergence of the above mentioned factors with the lowest decohesion resistance of the axial planes due to cold drawing explains why FIP testing anticipates in case of cracked specimens the type of crack extension that precedes, in the absence of hydrogen damage, plastic instability and subsequent tensile failure of the wires. The SEM close-up view given in Fig. 9 is showing the hydrogen assisted decohesion of the drawing texture. Hydrogen attack fronts are clearly marked, indicating that decohesion occurs in a series of successive local fractures, then the crack growth is axial and intermittent. Each new growth is produced by the applied load when hydrogen redistribution and concentration sufficiently embrittles the tip of the previous growth. This axial extension of the crack occurred at an average rate of $1.75 \cdot 10^{-9} \mathrm{~m} / \mathrm{s}$, which is 1000 times lower than that observed in the tensile testing of fatigue cracked specimens, hydrogen free.

Hydrogen damage concentrates at the crack tip, but it is not confined to this region. Fig. 10 shows axial secondary cracks developed from the fatigue fronts of the cracked surface during FIP testing.

\subsection{Effect of hydrogen assisted damage on damage tolerance}

The tensile testing of cracked wires shows that tensile failure is preceded by the axial extension of the crack. The posterior increase of the tensile load accelerates the plastic flow of the un-cracked ligament until plastic instability and necking are activated. The final fracture occurs by overloading, consisting of a ductile rupture on an inclined plane, as shown in Fig. 7a and b.

The damage tolerance of the wire does not change by the axial extension of the crack which develops as a preliminary stage in a purely mechanical failure process, or as hydrogen assisted damage in a stress corrosion process. The results of the above presented damage tolerance tests, added to those given in [2], provide a quantitative empirical basis to support this assertion. Table 3 contains the experimental data necessary to obtain the damage tolerance of the wires of which fracture tests are presented in Fig. 6, i.e., the dimensions of the cracks, and the tensile bearing capacities $P_{m}$. As previously indicated and reported in [2], the crack front was assimilated to a semiellipse with a symmetry axis tangent to the wire circumference (Fig. 1).

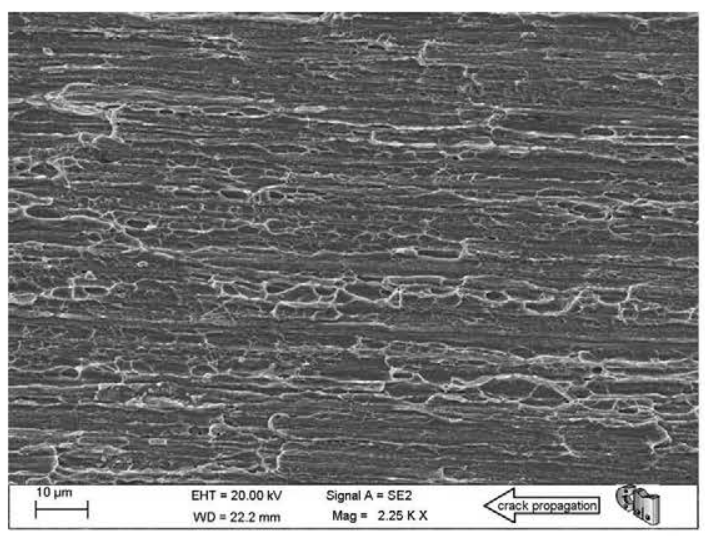

Fig. 8. Mechanically induced decohesion of the drawing texture at room temperature.

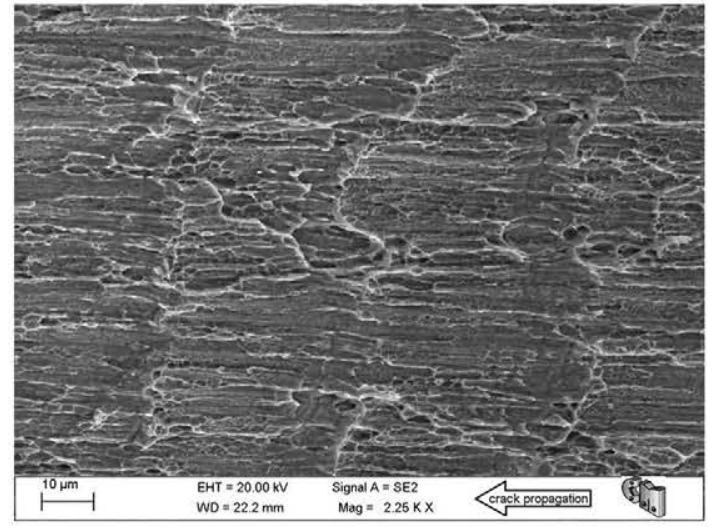

Fig. 9. Axial crack growth during FIP testing due to hydrogen induced decohesion of the drawing texture.

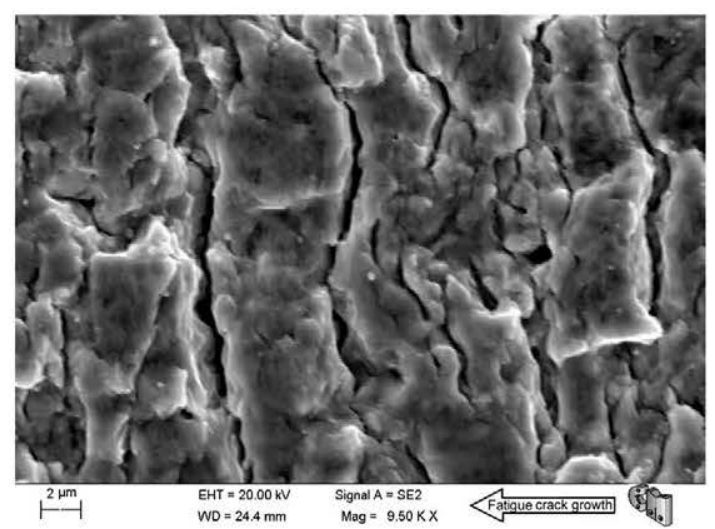

Fig. 10. Axial secondary cracks developed from the faces of the fatigue crack during FIP testing.

The damage tolerance curve presented in Fig. 11 is the experimental tensile bearing capacity of the cracked wires given as a function of the cracked area $A_{f}$. It is plotted in dimensionless terms, by using the cross sectional area $A_{0}$ of the wire and its tensile bearing capacity $P_{0}$ in the undamaged condition as units of the abscissa and ordinate axis, respectively. As it can be seen, all data follow the same trend, without any significant deviation between the hydrogen damaged specimens and the other ones.

The data plotted in Fig. 11 can be linearly fitted with a correlation coefficient of 0.991 :

$P_{m}=\left(0.995-1.05 \frac{A_{f}}{A_{0}}\right) P_{0}$

The option of using the ratio $A_{f} / A_{0}$ to describe the relative crack size and the linear relationship, given by Eq. (1), suggest another upper bound of the damage tolerance than that presented in [2], based on an elementary plastic collapse model of the cracked cross section. The previous model, which considers the bending moment induced by the asymmetry of the resistant ligament with respect to the wire axis, predicts an upper bound of damage tolerance in good agreement with that of eutectoid prestressing steel wires. According this plastic collapse model, expressed in terms of the ratio $A_{f} / A_{0}$, the predicted collapse load $P_{L}$ for crack fronts ranging from circular to straight can be approximated by:

$P_{L}=\left(1-\frac{A_{f}}{A_{0}}\right)^{2.1} P_{0}$

Eq. (2) is graphically represented in Fig. 11; it underestimates the experimental damage tolerance results of the tested cold drawn duplex steel wires, also plotted in Fig. 11. 
Table 3

Crack dimensions and failure loads of cracked wire specimens.

\begin{tabular}{llll}
\hline Crack dimensions and failure loads & $\begin{array}{l}\text { Hydrogen } \\
\text { damaged } \\
\text { specimens }\end{array}$ & $\begin{array}{l}\text { No hydrogen } \\
\text { damage } \\
\text { specimen }\end{array}$ \\
\hline$a$ - Crack depth $(\mathrm{mm})$ & 1.65 & 1.54 & 1.58 \\
$2 b$ - Distance between crack front ends $(\mathrm{mm})$ & 3.52 & 3.53 & 3.40 \\
$A_{f}$ - Cracked area $\left(\mathrm{mm}^{2}\right)$ & 4.09 & 3.84 & 3.79 \\
$P_{m}$ - Failure load $(\mathrm{kN})$ & 14.2 & 14.1 & 14.8 \\
\hline
\end{tabular}

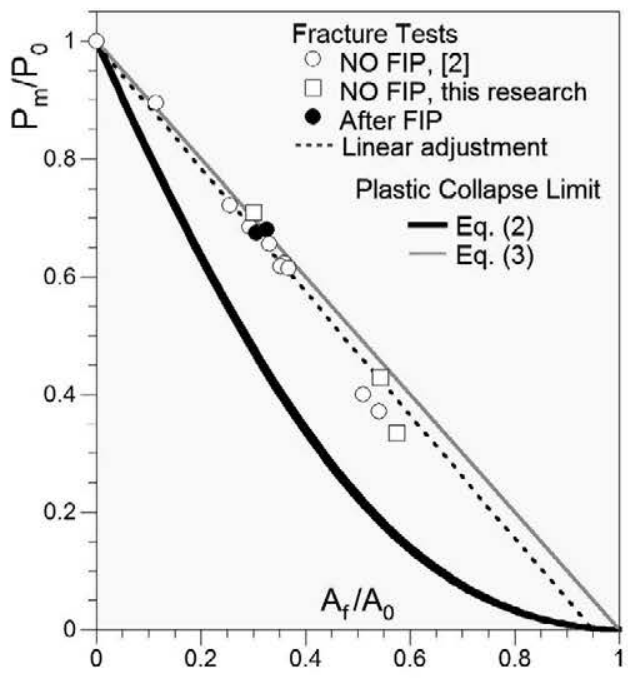

Fig. 11. Experimental damage tolerance of the tested cold-drawn 1.4462 steel wire including hydrogen damaged specimens and plastic collapse limits given by Eqs. (2) and (3).

In case of duplex steel wires, the collapse model can be modified by ignoring the bending moment, since the axial crack extension prior to the plastic instability of the resistant ligament provides the wire with enough local flexibility to transversally deflect until the centroid of the ligament lays on the wire axis. The ligament would plastically collapse in simple tension under the tensile load $P_{L}$ given by:

$P_{L}=\left(A_{0}-A_{f}\right) R_{m}=\left(A_{0}-A_{f}\right) \frac{P_{0}}{A_{0}}=\left(1-\frac{A_{f}}{A_{0}}\right) P_{0}$

where $A_{0}, A_{f}$ and $P_{0}$ have the same meanings as in Eq. (1), and $R_{m}$ is the tensile strength of the wires. The load $P_{L}$ of Eq. (3) differs less than $5 \%$ from the load given by Eq. (1).

According to Figs. 3 and 11, hydrogen assisted stress corrosion requires the aid of severe geometrical imperfections, such as the fatigue cracks used in this research, to induce macroscopic damage in the wire. Even so, the added damage does not produce quantitative changes in the mechanical behavior of the wires, since the steel is practically preserving its damage tolerance, as failure occurs by the plastic collapse of the resistant ligament.

\section{Conclusions}

The previous assessment of damage tolerance presented elsewhere for high strength wires made by deep cold drawing 1.4462 duplex stainless steel was extended for hydrogen assisted damage. Regarding the wire sensibility to this type of damage, the experimental results of the mechanical and FIP tests here provided show that:
- Damage does not initiate in un-cracked wires when loaded at $80 \%$ of tensile strength and exposed to the strongly hydrogen promoter FIP medium. The only detected effect was the strain hardening produced by the applied stress.

- The wires with artificially induced fatigue cracks long exposed to FIP environment and loaded up to $80 \%$ of their bearing capacity do not experience tensile failure. However, the cracks deflect along to the wire axis as a consequence of local hydrogen embrittlement and fracture anisotropy induced by cold drawing. This axial damage does not reduce the tensile resistance of the cracked wires. Its only effect is to shorten the process of tensile collapse, by reducing it to the plastic instability and necking of the resistant ligament.

The damage added by hydrogen assisted stress corrosion to the wires in as received condition and to the fatigue precracked ones does not alter their damage tolerance, i.e., the absolute upper bound of damage tolerance, given by the plastic collapse load of the resistant ligament in simple tension.

\section{Acknowledgements}

The authors gratefully acknowledge the partial financial support of the Spanish Ministry of Science and Innovation through the Project BIA 2011-26486 and the collaboration with INOXFIL S.A. who kindly provided the cold-drawn 1.4462 steel grade.

\section{References}

[1] EN10138-2 Standard. Prestressing steel - Part 2: Wire. European Committee for Standardization; 2009.

[2] Valiente A, lordachescu M. Damage tolerance of cold drawn ferritic-austenitic stainless steels wires for prestressed concrete. Constr Build Mater 2012;36:874-80.

[3] Nürnberger U. Influence of material and processing on stress corrosion cracking of prestressing steel - case studies. FIB bulletin 26. Féderation International du Béton; 2003. ISBN 2-88394-066-5.

[4] Bertolini L, Elsener B, Pedefemi P, Polder RP. Corrosion of steel in concrete. Weinheim: WILEY-VCH Verlag GmbH \& Co. KGaA; 2004, ISBN 3527-30800-8.

[5] Elices M. Influence of residual stresses in the performance of cold-drawn pearlitic steels. J Mater Sci 2004;39:3889-99.

[6] Mietz J, Isecke B. Assessment of test methods for evaluation stress corrosion cracking susceptibility of prestressing steels. Mater Corros 2002;53:373-84.

[7] Enos DG, Scully JR. A critical-strain criterion for hydrogen embrittlement of cold-drawn, ultrafine pearlitic steel. Met Mater Trans A 2002;33:1151-66.

[8] Ganz G, Nürnberger U. Effect of zinc on prestressing steel. FIB bulletin 64 . Féderation International du Béton; 2012. ISBN 978-2-88394-104-5.

[9] ISO/FDIS 15630-3. Steel for the reinforcement and prestressing of concretetest methods-Part 3: Prestressing steel. International Organization for Standardization; 2009.

[10] Elices M, Caballero L, Valiente A, Ruiz J, Martin A. Hydrogen embrittlement of steels for prestressing concrete: the FIP and DIBt tests. Corros J 2008;64:164-74.

[11] Nürnberger U, Wu Y. Stainless steels in concrete structures and in the fastening technique. Mater Corros 2008;59(2):144-58.

[12] Milad U, Zreiba N, Elahlouani F, Baradai C. The effect of cold work on structure an properties of AISI 304 stainless steels. J Mater Process Technol 2008;203:80-5.

[13] Moser RD. High-strength stainless steel for corrosion mitigation in prestressed concrete: development and evaluation. Ph.D. dissertation. Atlanta (Georgia, USA): Georgia Institute of Technology; 2011.

[14] Moser RD, Singh PM, Kahn LE, Kurtis KE. Preliminary studies of high-strength stainless steel. ACI SP 291: corrosion of reinforcing steel in concrete. American Concrete Institute; 2013. p. 95-104.

[15] Tavares SSM, da Silva MR, Pardal JM, Abreu HFG, Gomes AM. Microstructural changes produced by plastic deformation in the UNS S31803 duplex stainless steel. J Mater Process Technol 2006;180:318-22.

[16] Wu Y, Nürnberger U. Corrosion-technical properties of high-strength stainless steels for the application in prestressed concrete structure. Mater Corros 2009;60(10):771-80.

[17] Recio FJ, Wu Y, Alonso MC, Nürnberger U. Hydrogen embrittlement in colddrawn stainless steels. Mater Sci Eng A 2013;564:57-64.

[18] Moser RD, Singh PM, Kahn LE, Kurtis KE. Chloride induced corrosion resistance of high-strength stainless steel in simulated alkaline and carbonated concrete pore solutions. Corros Sci 2012;57:241-53. 
[19] Van Lelyveld CD, Van Bennekom A. An evaluation of two experimental duplex $\mathrm{Cr}-\mathrm{Mn}-\mathrm{N}$ stainless steels after thermo-mechanical processing. Mater Sci Eng A 1996;205:229-38.

[20] EN10088-3. Chemical composition of stainless steel. European Committee for Standardization; 2006.
[21] Nürnberger U. Corrosion induced failures of prestressing steel. Otto-Graf-] 2002;13:9-25.

[22] Turnbull A, Hutchings RB. Anlysis of hydrogen atom transport in a two-phase alloy. Mater Sci Eng A 1994;177:161-71. 